ing the other side, a further portion would be sent back as not only the one wing, but also the body and the second tables are for pure water, so that, when water contains ano another echo; if there were many alternate layers of air and wing, and not only the whole of one insect or fly, but the foreign matter, it will be necessary to multiply the tabular
carbonic acid gas, this action might take place so of ten as to whole of three of them which were mounted on one slide, weight by the specific gravity of the water. For ordinary carbonic acid gas, this action might take place so often as to whole of three of them which were mounted on one slide, weight by the specific gravity of the water. For ordinary
quench an entire wave of sound and todissipate it in echoes. and this with such good marginal definition as to permit the rain, spring. or river water, the currection is generally so Professor Tyndall here called attention to a small square spectators to advance to the screen and examine the details slight that it may be neglected. Below are given the specific wooden tube, into the air of which, he said, he could intro- through hand magnif ying glasses.

duce at will seven vertical sheets of carbonic gas through There is sold, in the watch glass makers' shops in Clerken. pipes. One of the sensitive flames, which contracted at a well, a foreign made watch glass of a peculiar kind, and " shrill sound, was placed at one end of the tube, and a whistle known in the trade as "concave crystal." The price we continuously blown by a bellows was placed at the other. paid was at the rate of five shillings a dozen, or more than When the tube contained air only, the sound passed freely $\mid$ six times that at which ordinary lunette glasses can be ob-

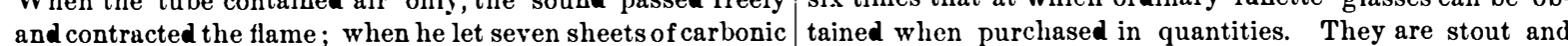
\begin{tabular}{l|l} 
and contracted the flame; when he let seven sheets of carbonic & tained when purchased in quantities. They are stout and \\
acid gas enter the tube, they broke up the sound into echoes & strong, the edges finely polished, and they are curved,spher-
\end{tabular} acid gas enter the tube, they broke up the sound into echoes
so that its action upon the thame was cut off, being intercepted
ically, to a very slight polished, and they are curved,spher so that its action upon the flame was cut off, being intercepted
by layers of invisible gas. He then showed that heated air
obtained were an inch and a half, and, instead of mounting would have the same effect,by doing away with the carbonic the objects which were intended to be subsequently magniacid, and placing four gas flames below the tube, so as to fied between two circular but flat glasses as usual, we heat it in four places, and produce four layers of heated air mounted then letween two of these "concave crystals." inside. Iayers of unequally heated air prevented the sound Here was the whole secret. The two glasses must be placed from passing through the tube, and broke it up into echoes. "spoon fashion," and the object,being between them, is bent The lecturer here remarked: "How could it be proved these in a gentle curve. With objects mounted in this way, and The lecturer here remarked: "How could it be proved these in a gentle curve. With objects mounted in this way, and layers produced echoes?" If they did so, of course he ought employing an objective of the kind we have just described-
to be able to prove it experimentally, so some time since he what is known by photographers as a "locket portrait com to be able to prove it experimentally, so some time since he what is known by photographers as a "locket portrait com-
asked his assistant to solve the problem practically, and Mr. bination" will answer well if of short focus-the lime light Cotterill had done so. His plan was to take a large hot flame need no longer be regarded as an indispensable requisite in from a batswing burner, which had the power of reflecting the showing of microscopic objects; for with a good lamp, sound, for the hotter the flame the greater was the reflection; burning paraffin oil, a disk of six feet may very easily be ob. and he placed this flame in a position to throw back the tained.

sound, which it actually did, as proved by the contraction of

the sensitive flame. $\quad$ tice we have also used this arrangement in connection with Strange than calico, muslin, and other woven fabrics. Professor ture, which should be microscopically sharp all over the area
Tywdall here borrowed a little boy's handkerchief, and of delineation, and, conversely, of producing enlargements Tyudall here borrowed a little boy's handkerchief, and of delineation, and, conversely, of producing enlargements
showed that it would not cut off the sound even when folded from pictures thus obtained. As respects the exposure re\begin{tabular}{l|l} 
showed that it would not cut off the sound even when folded & from pictures thus obtained. As respects the exposure re- \\
four times; neither would green baize, nor felt $\frac{1}{2}$ inch thick & quired to produce an absolutely sharp picture, it is, com-
\end{tabular} -so thick that it would entirely cut off the light of the pared with that which is necessary on a flat plate, less than noonday sun. Two hundred layers of muslin in a square pad half, because in the latter case a stop must be used to sehad but a feeble power in cutting off sound. The lecturer cure intense definition at the margin; hence if proper meremarked that this was because the air was continuous in. chanical contrivances be adopted for effecting a rapid exside the fabrics. On wetting the handkerchief with water $\begin{aligned} & \text { posure, there will be no difficulty in taking a fully exposed } \\ & \text { negative of any scene in which instantaneity is a pre-requi }\end{aligned}$ wet handkerchief cut off the sound. Ile remarke that, after site, the picture afterwards bearing a great degree of enseeing these facts, the listeners would be quite prepared to largement. After several trials we can assert with confseeing these facts, the listeners would be quite prepared to largement. After several trials we can assert with conf
understand that a heavy snow storm would have little power dence that the manipulation of a circular and slightly conunderstand that a heavy snow storm would have little power dence that the manipulation of a circular and slightly con-
in intercepting sound, whereas loud noises might be quickly : cave surface is quite as easy as that of a flat glass.-British in intercepting sound, whereas loud noises might be quickly: cave surface is quite as
quenched on a clear day, supposing the air to be leated un. Journal of Photography.

equally in different places.

Professor Tyndall narrated how in oneof his laboratory experiments he had placed fifteen layers of calico, each an inch or $t$ wo behind the other and in front of one of his sensitive flames. He discovered that the sound from the whistle would pass through the whole of the fifteen layers, and that each layer would reflect a portion of it so as to act upon the sensitive flame; thus in passing and returning through the fifteen layers, the sound passed through thirty layers in all.

fifteen layers, the sound passed through thirty layers in all.
Professor 'Tyndall here took a large glass cabinet,about the size of a watchman's box, and he caused the sound from the whistle to enter it on one side, and to depress the sensitive flames when it escaped on the other. In the lower part of the cabinet inside he lit two large gas flames, and the hot
air from these, rising in the calinet, intercepted the sound, air from these, rising in the calinet, intercepted the sound, that invisible columns of heated air would cut off sound. He then put out the burners and lit a piece of phosphorus placed in a saucer at the bottom of the cabinet; the latter of course was soon filled with a thick smoke of 'phosphoric acid-so thick was it, that it cut off from view a lighted candle which was placed at the back of the calinet; yet this cloud, which was so powerful in cutting off the rays of light, did not in terrupt the waves of sound at all. Having thus proved that invisible warm air may act as an acoustic cloud, he said that,
when such clouds are close to the source of sound, the echoes are immediate, and mix with the original sound; but if the acoustic clouds are further off, then there are prolonged echoes. Further, the length of an echo is a measure almost of the depth of the acoustic cloud whence it come.; In the experiments at the South Foreland, he discovered that, when a sound penetrated to a great distance,then tbe echoes when a sound
were longest.

were longest.
At the close of his lecture he argued that the phenomenon which Arago could not explain was due to warm air from the chimneys of Paris, forming acoustic clouds which surrounded the station at Villejuif, while the other station at Monthlery was free from this heterogeneous atmosphere.

\title{
The Micro-Lantern.
}

Discarding the usual microscopic low powers, we have now adopted, with increased advantages, an objective constructed on the same principle as the well known portrait combination, very short in focus, and with a large aperture in lenses are mounted is very short, so as to permit of the passage of a ray at a great degree of obliquity to the axis. This enables the objective power to cover a large field, or, speak ing inversely, to project an image of large dimensions compared with its focal power. But no one who has bestowed
attention upon the transmission of large oblique pencils will attention upon the transmission of large oblique pencils will
fail to see that, if the object to be enlarged were mounted upon a flat glass, the astigmation would be so great that, while there would be plenty of light,there would be no marginal defiation worthy of the term in the enlarged image.
This is quite true; hence we will afford of the manner by which we so managed that, whereas by one of the usual microscopic objectives only one extended one of the usual microscopic objectives only one extended
wing of a grasshopper was shown on the screen, we showed accurate for most purposes. The weights given in the umes as to render internolations by proportion sufficiently

THE VOLUME AND WEIGHT OF DISTILLED WATER AT DIFFERENT TEMPERATURES.

$$
\text { BY RICHARD B. BUEL. }
$$

In general, water expands when heated, and contracts on being cooled-with the exception that the greatest contraction ccurs when the water has a temperature of about $39^{\circ} \mathrm{Fah}$., so
that expansion takes place whether the temperatureis decreasthat expansion takes place whether the temperature is decreasd or raised a bove this point. The precise temperature at which
water attains its maximum density has not been accurately determined. The differences between the results obtained by independent investigations are, however, very slight, and the point of maximum density is commonly taken at $39 \cdot 2^{\circ} \mathrm{Fah}$., or $4^{\circ}$ on the centigrade scale. At this temperature, the weight of
a cubic foot of distilled water, as determined by the best authorities, is $62.425 \mathrm{lbs}$; t the weight of a United States gallon is $8.379927 \mathrm{lbs}$., of an imperial gallon, $10.05312 \mathrm{lbs}$., and of a cubic inch, $252 \cdot 8787$ grains. In French measures, it is usually assumed that a cubic decimeter of distilled water
weighs 1 kilogramme. This is not strictly accurate, owing to a slight error, in regard to the weight of water of maximum density, which was made at the time of fixing the measure; kilogramme of pure water at the temperature of maximum density. In I,ractice, however, the volume of a liter is commonly assumed to be one cubic decimeter, and the erroraris g from this assumption is unimportant, being less than not regular for equal increments of temperature, but the aw of the expansion has been determined by numerous ex-
perimenters, the most prominent of whom are Iiopp, Matthiessen, Sorby, and liusetti. The formulas constructed from their experiments are given below, being taken from Watt's " Dictionary of Chemistry."

Let $\mathrm{V}=$ ratio of a given volume of distilled water, at the temperature, ' $\Gamma$, on Fahrenheit's scale, to the volume of an qual weight, at the temperature of maximum density.

\section{any temperature, Fahrenheit.}

For temperatures from $32^{\circ}$ to $70^{\circ}$ Fah. : $\mathrm{V}=1 \cdot 0001$ $0.000033914 \times(\mathrm{T}-32)+0.000023822 \times(\mathrm{T}-32)^{2}-0.0000000$ $403(\mathrm{~T}-32)^{3}$.

For temperatures above $70^{\circ}$ Fah. : $\mathrm{V}=0.99781+0.000061$ $\mathrm{IV}=\frac{62 \cdot 425}{\mathrm{~V}}$

The table given below has been computed by the aid of hese formulas. The experiments on the expansion of water have not been carried beyond a temperature of 412 Fah., so that the results given in the table for higher tem-
peratures have not been verified. It is not probable, however, that they are greatly in error. The highest tem. perature in the table corresponds to a pressure of saturatsteam of more than $1,000 \mathrm{lbs}$. per square inch. The sucssive increments of $10^{\circ} \mathrm{Fah}$. give such slight changes amount of oil requisite for the oiling process is reduced 50 pe accurate for most purposes. The weights given in the $\mid$ cent. The above is the subject of an English patent. gallons water and 3 pounds of commercial sulphuric acid; it
$1 \cdot 0275$ $1 \cdot 1720$

Dead Sea.

Treat Salt Lake

Mississippi River

Croton (New York Water Supply)

Ridgewood (Brooklyn Water Supply)
Cochituate (Boston Water Supply).

Schuylkill (Philadelphia Water Supply).

Delaware River. ...

Lake Erie.....

Lake Michigan.

Genesee River...

Thames, at London.

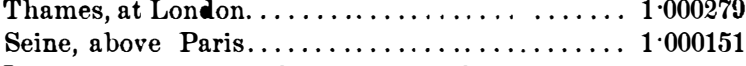

It will be seen from these figures that, for most cases, it table. If the weight of a gallon of water at any tempera. ture is desired, it may be obtained by dividing the weight of gallon of water at the temperature of maximum density, previously given, by the relative vol ume at the required tem. of a cubic foot of water, at the given temperature, by 0.13368 o find the weight of a United States gallon, and ly $0 \cdot 160372$ find the weight of an imperial gallon. When water contains foreign matter in solution, its rate of expansion by heat
is not exactly the same as in the case of distilled water. There has not been a sufficiency of experiments, however, to determine the law of the variation, and no great error will
arise from the assumption that the expansion is in accordance with the formulas given above.

Withthese explanations, the use of the following table will be rendered plain to the reader

VOUME AND WEIFHT OF DISTILLED WATER AT DIFFEKENT TEMPERATURES $\odot$ T THE FAIHLNHEIT SCALE.

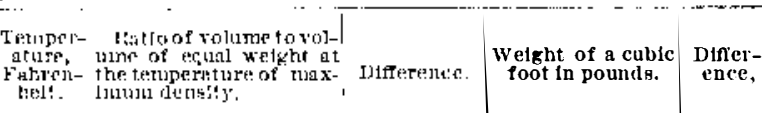

\begin{tabular}{|c|c|c|c|c|c|}
\hline $332=$ & $1 \cdot 000129$ & & & $(i 2-417$ & \\
\hline 3 & $1 \cdot 000000$ & $\cdot 000129$ & & $62 \cdot 42 \bar{J}$ & $\cdot 008$ \\
\hline $4\left(j^{\circ}\right.$ & $1 \cdot 000004$ & $\cdot 000004$ & & $62 \cdot 423$ & 002 \\
\hline $50^{\circ}$ & $1 \cdot 000253$ & $\cdot 000249$ & & $62 \cdot 409$ & $\cdot 014$ \\
\hline $60^{\circ}$ & $1 \cdot 000929$ & $\cdot 000676$ & & $62 \cdot 367$ & $\cdot 042$ \\
\hline $70^{\circ}$ & $1 \cdot 001981$ & $\cdot 001052$ & & $62 \cdot 302$ & $\cdot 06 \pi$ \\
\hline $80^{\circ}$ & $1 \cdot 00332$ & $\cdot 001339$ & & $62 \cdot 218$ & .084 \\
\hline $90^{\circ}$ & $1 \cdot 00492$ & $\cdot 00160$ & & $62 \cdot 119$ & 699 \\
\hline $100^{\circ}$ & $1 \cdot 00686$ & $\cdot 00194$ & & $62 \cdot 000$ & $\cdot 119$ \\
\hline $110^{\circ}$ & $1 \cdot 00902$ & $\cdot 00216$ & & $61 \cdot 867$ & -13:3 \\
\hline $120^{\circ}$ & $1 \cdot 01143$ & $\cdot 00241$ & & $61 \cdot 720$ & $\cdot 14 \bar{\tau}$ \\
\hline $130^{\circ}$ & $1 \cdot 01411$ & $\cdot 00268$ & & $61 \cdot 556$ & $\cdot 164$ \\
\hline $140^{\circ}$ & $1 \cdot 01690$ & $\cdot 00279$ & & $61 \cdot 388$ & .168 \\
\hline $150^{\circ}$ & $1 \cdot 01995$ & $\cdot 00305$ & & $61 \cdot 204$ & $\cdot 184$ \\
\hline $160^{\circ}$ & $1 \cdot 02324$ & $\begin{array}{l}\cdot \cdot 00329 \\
\end{array}$ & & $61 \cdot 007$ & $\cdot 19 \pi$ \\
\hline $170^{\circ}$ & $1 \cdot 02671$ & $\cdot 00347$ & & $60 \cdot 801$ & $\cdot 206$ \\
\hline $180^{\circ}$ & $1 \cdot 03033$ & $\cdot 00362$ & & $60 \cdot 587$ & $\cdot 214$ \\
\hline $190^{\circ}$ & $1 \cdot 03411$ & $\cdot 00378$ & & $60 \cdot 36 i$ & $\cdot 221$ \\
\hline $200^{\circ}$ & $1 \cdot 03807$ & $\begin{array}{ll}\cdot 00396 \\
\end{array}$ & & $60 \cdot 136$ & .230 \\
\hline $210^{\circ}$ & $1 \cdot 04226$ & $\cdot 00419$ & & $59 \cdot 894$ & $\cdot 242$ \\
\hline $212^{\circ}$ & 1·04312 & $\cdot 00086$ & : & $59 \cdot 707$ & $\cdot 197$ \\
\hline $220^{\circ}$ & $1 \cdot 04668$ & $\cdot 00356$ & & $59 \cdot 641$ & $\cdot 066$ \\
\hline $230^{\circ}$ & $1 \cdot 0.5142$ & $\cdot 00474$ & & $59 \cdot 372$ & $\cdot 269$ \\
\hline $240^{\circ}$ & $1 \cdot 05633$ & $\cdot 00491$ & & $59 \cdot 096$ & $\cdot 2 \pi 0$ \\
\hline $2: 5)^{\circ}$ & $1 \cdot 06144$ & $\cdot 00511$ & & $58 \cdot 812$ & $\cdot 284$ \\
\hline $260^{\circ}$ & $1 \cdot 06679$ & $.0053 \tilde{5}$ & & $58 \cdot 517$ & . $29 \pi$ \\
\hline $2 \pi 0^{\circ}$ & $1 \cdot 07233$ & $\cdot 00554$ & & $58 \cdot 214$ & $\cdot 303$ \\
\hline $280^{\circ}$ & $1 \cdot 07809$ & $\cdot 00576$ & & $57 \cdot 903$ & $\cdot 311$ \\
\hline $290^{\circ}$ & $1 \cdot 08405$ & $\cdot 00596$ & & $57 \cdot 58.5$ & $\cdot 318$ \\
\hline $300^{\circ}$ & $1 \cdot 09023$ & $\cdot 00618$ & & $57 \cdot 259$ & $\cdot 326$ \\
\hline $310^{\circ}$ & $1 \cdot 09661$ & $\cdot 00638$ & & $56 \cdot 925$ & $\cdot 334$ \\
\hline $320^{\circ}$ & $1 \cdot 10323$ & $\cdot 00662$ & $!$ & $56 \cdot 584$ & $\cdot 341$ \\
\hline $3: 31^{\circ}$ & $1 \cdot 11005$ & $\cdot 00682$ & & $56 \cdot 236$ & $\cdot 348$ \\
\hline $340^{\circ}$ & $1 \cdot 11706$ & .00701 & & $5.5 \cdot 883$ & .353 \\
\hline $3 ; \pi^{\circ}$ & $1 \cdot 12431$ & $\cdot 0072, \overline{7}$ & & $55 \cdot 523$ & $\left.\cdot 36^{\prime \prime}\right)$ \\
\hline $360^{\circ}$ & $1 \cdot 13175$ & $\cdot 00744$ & & $5.5 \cdot 1.78$ & $\cdot 365$ \\
\hline $3 \pi 0^{\circ}$ & $1 \cdot 13942$ & $\cdot 00767$ & & $54 \cdot 787$ & - \\
\hline $380^{\circ}$ & $1 \cdot 14 i 29$ & $\cdot 00787$ & & $54 \cdot 411$ & $\cdot 3 \pi 6$ \\
\hline $390^{\circ}$ & $1 \cdot 15538$ & $\cdot 00809$ & & $54 \cdot 0: 30$ & $\cdot 381$ \\
\hline $400^{\circ}$ & $1 \cdot 16366$ & $\cdot 00828$ & & $53 \cdot 645$ & $\cdot 385$ \\
\hline $410^{\circ}$ & $1 \cdot 17218$ & .00852 & & $53 \cdot 25 \%$ & $\cdot 390$ \\
\hline $420^{\circ}$ & $1 \cdot 18090$ & $\cdot 00872$ & & $52 \cdot 862$ & $\cdot 393$ \\
\hline $430^{\circ}$ & $1 \cdot 18982$ & $\cdot 00892$ & & $52 \cdot 466$ & $\cdot 396$ \\
\hline $440^{\circ}$ & $1 \cdot 19898$ & .00916 & & $52 \cdot 065$ & $\cdot 401$ \\
\hline $450^{\circ}$ & $1 \cdot 20833$ & $\cdot 00935$ & & $51 \cdot 662$ & $\cdot 403$ \\
\hline $460^{\circ}$ & $1 \cdot 21790$ & $\cdot 00957$ & & $51 \cdot 256$ & $\cdot 40$ \\
\hline $4 \pi 0^{\circ}$ & $1 \cdot 22767$ & $\cdot 00977$ & & $50 \cdot 848$ & $\cdot 408$ \\
\hline $480^{\circ}$ & $1 \cdot 23766$ & $\cdot 00999$ & & $50 \cdot 438$ & $\cdot 410$ \\
\hline $490^{\circ}$ & $1 \cdot 2478 \tilde{\jmath}$ & .01019 & & $50 \cdot 026$ & .412 \\
\hline $500^{\circ}$ & $1 \cdot 25828$ & $\cdot 01043$ & & $49 \cdot 611$ & $\cdot 415$ \\
\hline $510^{\circ}$ & $1 \cdot 26892$ & $\cdot 01064$ & & $49 \cdot 195$ & : \\
\hline $520^{\circ}$ & $1 \cdot 27975$ & .010 & & $48 \cdot 778$ & 7 \\
\hline $530^{\circ}$ & $1 \cdot 29080$ & $\cdot 01105$ & & $48 \cdot 360$ & $\cdot 418$ \\
\hline $540^{\circ}$ & $1 \cdot 30204$ & $\cdot 01124$ & & $47 \cdot 941$ & $\cdot 419$ \\
\hline $550^{\circ}$ & $1 \cdot 31354$ & $\cdot 01150$ & & $47 \cdot 521$ & $\cdot 420$ \\
\hline
\end{tabular}

Preparation of wool before Carding.

Messrs. Whittaker and Ashworth state that this operation effects an economy in oil in the usual process of oiling the wool. The first treatment is in an alkaline bath. The wool is then worked for one or two minutes in an acid bath, at a emperature of about $99^{\circ} \mathrm{Fah}$. This bath is composed of 200 wool is now carefully washed and dried. Thus prepared, the 